\title{
Effect of size-selective photoetching on the absorption and photoluminescence spectra of CdSe nanoparticles
}

\author{
${ }^{1}$ Davydenko M.O., ${ }^{1}$ Dmitruk I.M., ${ }^{1}$ Pundyk I.P., ${ }^{1}$ Berezovska N.I. and \\ ${ }^{2}$ Romanyuk V.R. \\ ${ }^{1}$ Kyiv National Taras Shevchenko University, 2 Academician Glushkov Ave., \\ Building 1, 03680 Kyiv, Ukraine \\ ${ }^{2}$ Institute for Physics of Semiconductors, National Academy of Sciences of \\ Ukraine, 45 Nauky Ave., 03028 Kyiv, Ukraine
}

Received: 24.06.2010

\begin{abstract}
Peculiarities of the absorption and photoluminescence (PL) spectra of colloidal solution of CdSe nanoparticles have been studied in the process of size-selective photoetching. The values of homogeneous broadening and lifetime of resonantly excited exciton states in nanoparticles of definite sizes have been estimated. A model explaining the nature of Stokes shift has been suggested, which takes into account inhomogeneity of energy of the electron-hole pair in the volume of nanoparticle. The Stokes shift values have been determined for different samples. Different changes in the PL spectra observed during the process of photoetching could be caused by the influence of different initial defect structures of the samples.
\end{abstract}

Keywords: CdSe nanoparticles, size-selective photoetching, Stokes shift.

PACS: 81.16.Be, 73.22.-f, 78.67.Bf

UDC: $535.343,535.37$

\section{Introduction}

Nanoparticles in semiconductors are currently being one of the most studied subjects due to their unique physical properties which can be very different from those of the corresponding bulk materials. In spite of a large number of studies, some fundamental properties of those nanoparticles still remain to be studied in a more detail. One of the main difficulties is a problem of synthesis of nanostructures with the nanoparticles of the same sizes and structures. The best techniques elaborated up to date [1-4] allow obtaining ensembles revealing the size distribution of about $10 \%$ [1], though even such a narrow dispersion complicates much the studies of electronic processes in semiconductor nanoparticles.

Chemical techniques for the nanoparticle synthesis are easy to implement and flexible enough for the synthesis of nanoparticles with different sizes and shapes, however the size distribution of the as-grown particles is often far from desirable. The techniques usually used to improve the size distribution, such as a liquid-phase chromatography, a size-selective precipitation and some others, are based on the same idea, namely a separation of the particles of specified sizes from a broad as-grown 
ensemble. These methods enable one to improve the size distribution down to 5\% [1]. Nonetheless, their characteristic feature is a small yield of the particles of necessary size.

A technique of size-selective photochemical etching is considered as promising for the preparation of desired amount of nanoparticles of specified sizes. Here the idea is to decrease the size of bigger particles in the ensemble to that of the smallest ones, thus preserving a total number of the particles. A high photosensitivity of colloidal solutions has been known long time ago, though the first comprehensive study of chemistry of the etching process and its possible applications for controlled decrease of the size of semiconductor nanoparticles has been presented only in the work [5]. Later on, several groups of researchers have demonstrated that it is possible not only to decrease the particle sizes but to obtain narrower size distributions for $\mathrm{CdS}[6,7]$ and some other semiconductors $[8,9]$.

Application of the size-selective photoetching allows both producing nanoparticles and studying their fundamental properties [10]. It helps to resolve the excited states of electron-hole pairs in the nanoparticles and estimate a homogeneous broadening of the exciton absorption peak and Stockes shift of exciton transition. The nature of the Stokes shift for the semiconductor nanoparticles in the strong confinement limit still lacks unambiguous explanations. The most appropriate model has been proposed in the work [11]. The Stokes shift is determined as splitting between the lowest optically active bright exciton state and the optically passive dark exciton ground state. This distance increases with decreasing particle size and ranges from $\sim 20 \mathrm{meV}$ for small crystals to $\sim 2 \mathrm{meV}$ for large ones. The photoetching increases the quantum yield of photoluminescence (PL) via increasing charge carrier lifetime in the nanoparticles.

In the present paper we study the peculiarities of changes in the absorption and the PL spectra of colloidal solution of the CdSe nanoparticles occurring under irradiation with argon ion laser in the process of size-selective photoetching.

\section{Experimental}

CdSe nanoparticles were prepared by a wet chemical method in reverse micelles put in toluene $[12,13]$. Sodium selenosulphate $\left(\mathrm{Na}_{2} \mathrm{SeSO}_{3}\right)$, referred to as a solution 1, was used as a source of $\mathrm{Se}^{2-}$ ions. The solution 1 was prepared by vigorous stirring of $\mathrm{Se}(99 \%)$ with $\mathrm{Na}_{2} \mathrm{SO}_{3}$, performed in a distilled water at $70^{\circ} \mathrm{C}$ for about two days. A solution referred to as solution 2 was obtained while dissolving $\mathrm{CdSO}_{4}$ and a complexing agent in water (Trilon B was used for samples of type 1 and SNTA for samples of type 2), methanol (samples of type 1) or ethanol (samples of type 2), using a decylamine $\mathrm{CH}_{3}\left(\mathrm{CH}_{2}\right)_{9} \mathrm{NH}_{2}$ as a surfactant.

The amine groups of the surfactant and the chelating agent molecules form complexes with metal ions, which prevent $\mathrm{Cd}^{2+}$ from oxidation in aqueous solution and from fast uncontrolled reaction with $\mathrm{Se}^{2-}$ ions. The solutions 1 and 2 are mixed with the following injection of toluene. Once the toluene is added to this solution, the micelles move up into the toluene and transform into reverse micelles, in which nucleation and 
further growth of nanoparticles takes place at the temperatures higher than $45^{\circ} \mathrm{C}$. Growth of the particle ends as soon as heating is switched off.

In this paper we present the data for the samples of the two types which have been prepared with a wet chemical method and demonstrate different types of behaviour of the PL spectra in the process of selective photoetching.

Optical measurements were performed at a room temperature using a setup based on MDR-3 monochromator. Colloidal solution of the CdSe nanoparticles was placed into a quartz cylinder cell with the diameter of $10 \mathrm{~mm}$. The absorption spectra were obtained relative to the pure toluene. The PL spectra were measured at a $90^{\circ}$-geometry, using a nitrogen laser excitation (the light wavelength of $\lambda=337.1 \mathrm{~nm}$, the repetition rate $50 \mathrm{~Hz}$, and the average power $3 \mathrm{~mW}$ ). During the etching, the samples were irradiated with an argon ion laser $(\lambda=488 \mathrm{~nm})$.

The absorption and PL spectra of the initial colloidal solution of CdSe nanoparticles were measured prior to the etching. Then the solution was irradiated during 15-60 s, and the absorption and PL spectra were recorded again. The procedure was repeated up to 10 times. The total etching time for each sample was equal to 15-20 min.

A dependence of the energy of electron transition between quantised levels of the valance and conduction bands upon the particle size was used for estimation of the average particle size. The existing theoretical models, such as an effective-mass approximation and tight-binding calculations, predict the corresponding values which agree quite well with the experimental data for the nanoparticle sizes of about $2 \mathrm{~nm}$. However, these approximations are very time-consuming and provide a limited precision. Moreover, the theoretical results start to deviate notably from the experimental values for the particle sizes less than $2 \mathrm{~nm}$. That is why we have used a simple empirical relation between the diameter of CdSe nanoparticles and the exciton peak position [13]:

$$
d[\mathrm{~nm}]=0.344 \exp \left(\frac{\lambda_{\max }[\mathrm{nm}]-252.7}{129.3}\right) .
$$

Dispersion of the nanoparticle sizes $\Delta d / d$ in the ensemble can be estimated issuing from the full width at half maximum (FWHM) of the absorption peak, which includes both homogeneous and inhomogeneous broadening. The homogeneous broadening could be determined from the photoetching experiments themselves (see a detailed explanation below). The inhomogeneous broadening is mainly caused by a size distribution of the nanoparticles in solution. The dispersion of nanoparticle sizes $\Delta d$ in the ensemble is calculated as a difference between the FWHM of the absorption peak and the homogeneous broadening.

\section{Results and discussion}

In our photoetching experiments colloidal solutions of the CdSe nanoparticles have been investigated, with the average size of $1.6-1.8 \mathrm{~nm}$ and the size distribution of $29-31 \%$. After the photoetching procedure, the size distribution has been improved to $7-13 \%$. As the saturation has not been reached, still narrower size distributions could be obtained 
under further photoetching. However, since in this work we consider the effects which become apparent at the initial stage of the photoetching process, we have not planned to achieve the highest possible improvement of the size distribution.

Fig. 1 and Fig. 2 show respectively the absorption spectra obtained for the colloidal solutions of CdSe nanoparticles of the types 1 and 2. In the absorption spectrum for the sample of the type 1 (see Fig. 1, curve $a$ ) we observe a peak with a maximum located at $450 \mathrm{~nm}$, which corresponds to the particles with the average size of $1.6 \mathrm{~nm}$. The size distribution in the initial sample is equal to $31 \%$ and decreases to $13 \%$ after irradiation during $15 \mathrm{~min}$. A peak with a maximum at $464 \mathrm{~nm}$ revealed in the absorption spectrum for the sample of the type 2 (Fig. 2, curve $a$ ) corresponds to the nanoparticles having the average size of $1.8 \mathrm{~nm}$. In this case the size distribution also decreases from $29 \%$ to $7 \%$ after irradiation during $15 \mathrm{~min}$.

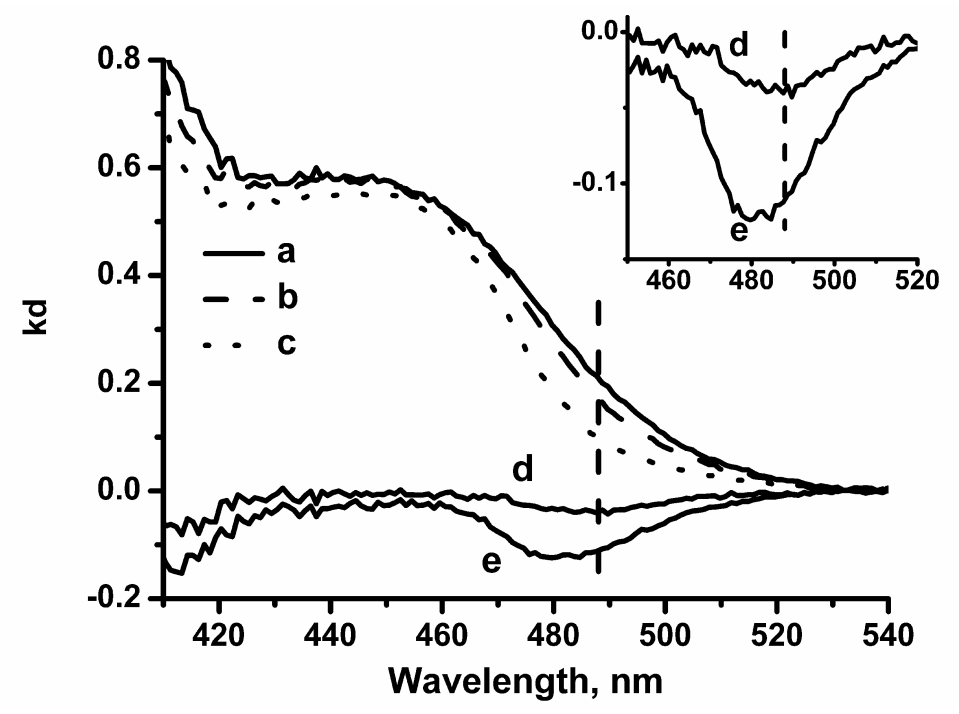

Fig. 1. Absorption spectra of the type 1 colloidal solution of CdSe nanoparticles: $a$ - the initial spectrum, $b$ and $c$ - the same spectra obtained after $1 \mathrm{~min}$ and $5 \mathrm{~min}$ of photoetching, respectively. Curves $d$ and $e$ represent differences of the absorption spectra of the colloidal solution under photoetching during 1 and $5 \mathrm{~min}$, respectively, and the initial spectrum. The insert shows curves $d$ and $e$ in enlarged scale. Dashed vertical line marks a position of the argon ion laser line used for the etching.

A dip on the differential spectral curves is observed in the region of photoetching (see Fig. 1 and Fig. 2, curves $d$ and e). The half-width of that dip at the initial etching stage is determined by a homogeneous broadening, similar to the experiments on "hole burning" [14]. This gives a possibility to evaluate a lifetime $\tau=h / \Delta E$ of the electron-hole pair obtained due to absorption of a light quantum [10]. This is the lifetime of resonantly excited electron-hole pair in the state, in which the absorption directly occurs. Such a parameter may also be called as a coherence conservation time. This lifetime is determined by relaxation of the electron-hole pair to a lower energy due to interaction with phonons and, as a result, a loss of coherence. The homogeneous broadening is $30 \mathrm{~nm}$ 
(15.7 meV) for the CdSe nanoparticles of the type 1 and so the lifetime is of the order of $39 \mathrm{fs}$, whereas for the CdSe nanoparticles of the type 2 we have the following values: $25 \mathrm{~nm}(13.0 \mathrm{meV})$ and $30 \mathrm{fs}$.

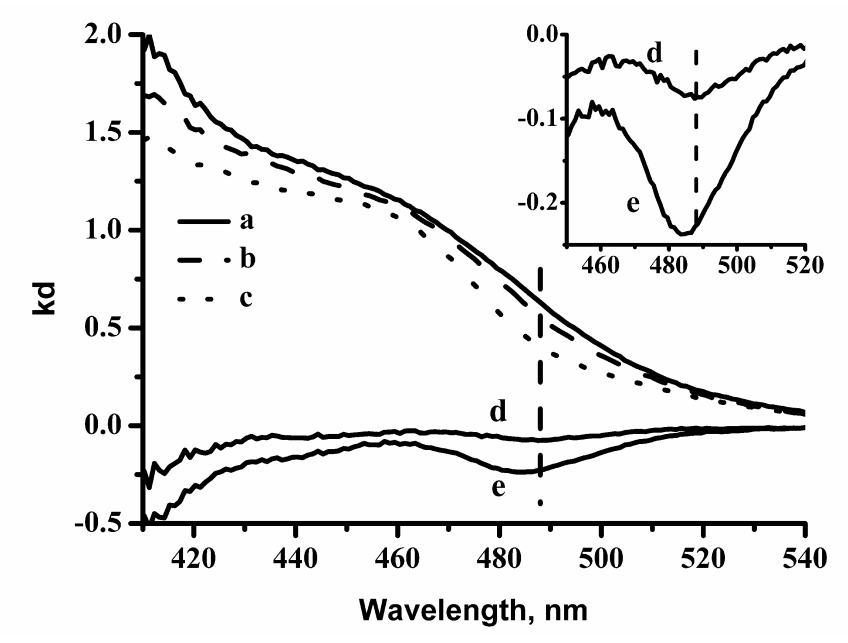

Fig. 2. Absorption spectra of the type 2 colloidal solution of CdSe nanoparticles: $a$ - the initial spectrum, $b$ - the spectrum obtained after 2 min of photoetching, and $c$ - the same after $10 \mathrm{~min}$ of photoetching. Curves $d$ and $e$ represent differences of the absorption spectra of the colloidal solution detected under photoetching during 2 and $10 \mathrm{~min}$, respectively, and the initial spectrum. The insert shows curves $d$ and $e$ in enlarged scale. Dashed vertical line marks a position of the argon ion laser line used for the etching.

At the initial etching stage (less than 1 minute) the dip minimum corresponds to the wavelength of $488 \mathrm{~nm}$ used for the etching. Therefore only the particles, of which transition energy is equal to that of the laser emission quantum, take part in the process at the beginning of the experiment. Hence, due to the resonant absorption occurring at the initial stage of irradiation, the etching process takes place mainly in the resonantly excited particles. Under further etching, when a contribution of the nonresonant absorption sufficiently grows, the dip minimum shifts towards shorter wavelengths. It is clearly seen from the inserts of Fig. 1 and Fig. 2. In our opinion, this shift can indicate the etching of nanoparticles of some other size, for which the transition energy is out of resonance with the energy of line used for the etching. The nonresonant absorption of light by those nanoparticles involves phonons or defect states.

The PL spectra of the colloidal solutions of CdSe nanoparticles of the types 1 and 2 are shown in Fig. 3 and Fig. 4, respectively. As seen from Fig. 3, a single peak with a maximum located at $490 \mathrm{~nm}$ is revealed in the initial spectrum. This band shifts towards shorter wavelengths and reduces in intensity in the etching process. A dip with a minimum located at $500 \mathrm{~nm}$ is observed on the differential curves. The Stokes shift, being equal to $12 \mathrm{~nm}$, is estimated as a difference of this dip and the laser line.

Unlike to explanation of the Stokes shift mentioned above [11], we suggest a simpler model, which does not require involving of a concept of dark exciton. It takes into 
account inhomogeneity of the energy of electron-hole pair in the volume of the nanoparticle. In frame of this model, the nature of the Stokes shift is associated with vibrational relaxation of nonequilibrium confined excitons. When the exciton is created at

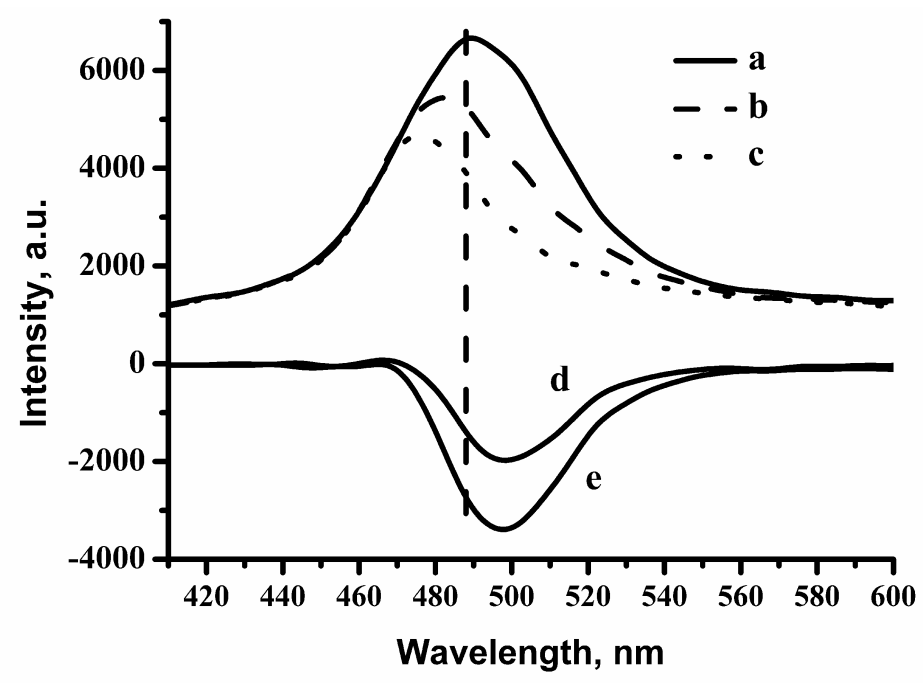

Fig. 3. PL spectra of the colloidal solutions of CdSe nanoparticles of the type 1: $a$ - the initial spectrum, $b$ - the spectrum obtained after 1 min of photoetching, and $c-$ the same after 5 min of photoetching. Curves $d$ and $e$ represent differences of the PL spectra of the colloidal solution detected under photoetching during 1 and $5 \mathrm{~min}$, respectively, and the initial spectrum. Dashed vertical line marks a position of the argon ion laser line used for the etching.

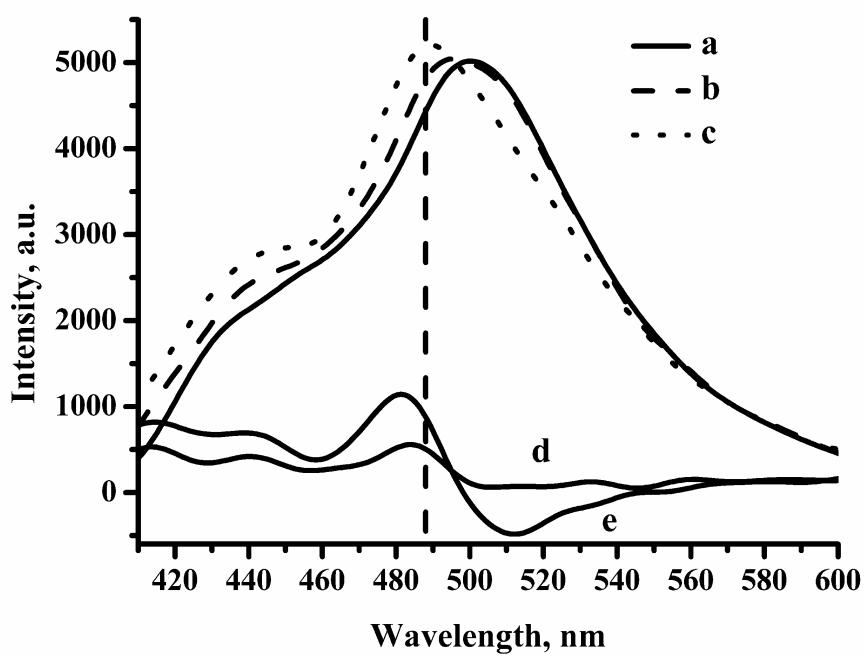

Fig. 4. PL spectra of the colloidal solutions of CdSe nanoparticles of the type 2: $a$ - the initial spectrum, $b$ - the spectrum obtained after 2 min of photoetching, and $c-$ after $10 \mathrm{~min}$ of photoetching. Curves $d$ and $e$ represent differences of the PL spectra of the colloidal solution detected under photoetching during 2 and $10 \mathrm{~min}$, respectively, and the initial spectrum. Dashed vertical line marks a position of the argon ion laser line used for the etching. 
the peripheral part of the nanoparticle, a further relaxation to the lowest energy state, where the electron is spread within the particle volume and the hole is localised at its centre, occurs via interaction with acoustical and optical phonons. The exciton energy loss, due to movement of the hole to the centre of the particle, corresponds to the Stokes shift value observed in the experiment. Notice that our model also allows one to explain the existence of periodic structure in the resonant low-temperature PL [15].

The PL spectrum for the sample 2 consists of two broad overlapping bands, with the maxima at 440 and $500 \mathrm{~nm}$ (see Fig. 4). It is seen from the comparison of absorption and PL spectra that the band with the maximum located at $500 \mathrm{~nm}$ corresponds to a band edge luminescence of the nanoparticles with the average size of $1.8 \mathrm{~nm}$, while in the absorption spectrum the particles of the size mentioned above determine the peak with the maximum at $464 \mathrm{~nm}$. The peak with the maximum at $440 \mathrm{~nm}$ corresponds to nanoparticles of smaller size which are also present in the colloidal solutions of CdSe nanoparticles of the type 2 . However, we observe no separate peak in the absorption spectrum which could be caused by these nanoparticles.

For the sample of type 2 one can see specific behaviour of the differential spectra of a type of "rosette", with the inflection point located in the range of $495 \mathrm{~nm}$, in contrast to the sample of type 1 where a single dip is observed on the differential curves. The width of the "rosette" increases in the process of photoetching. Some peaks in high-energy range of the differential curves could correspond to the excited states of the electron-hole pair, though this fact requires more detailed studies. The Stokes shift for this sample is equal to $7 \mathrm{~nm}$. It is evaluated as a difference between the laser line and the inflection point of the "rosette" which virtually does not change its position in the photoetching process, unlike the minimum which shifts to a low-energy side.

In our opinion, different changes observed in the PL spectra of CdSe nanoparticles should be apparently caused by different initial defect structures of different samples. For instance, the photoetching has no effect on the bulk defects which could prevail in the sample of the type 1. As a consequence, one can see a dip on the differential curves located in the region of the wavelength used for the etching. On the other hand, the surface defects are very likely to become dominant in the sample of the type 2 . Their quantity is then reduced owing to the photoetching. A decrease in the quantity of channels open for nonradiative recombination becomes apparent not only as a dip in the differential spectra but also as an increase observed in the PL.

\section{Conclusions}

In the present paper we have studied the peculiarities of transformations in the absorption and PL spectra of colloidal solutions of the CdSe nanoparticles occurred in the process of size-selective photoetching. The values of the homogeneous broadening and the lifetime of resonantly excited exciton states in the nanoparticles of specific sizes have been estimated. The homogeneous broadening is about $30 \mathrm{~nm}(15.7 \mathrm{meV})$ for the CdSe sample of the type 1 and the lifetime is approximately equal to $39 \mathrm{fs}$. The same parameters for the sample of the type 2 are $25 \mathrm{~nm}(13.0 \mathrm{meV})$ and $30 \mathrm{fs}$. 
The Stokes shift is determined to be 7 and $12 \mathrm{~nm}(3.6$ and $6.2 \mathrm{meV})$ for different samples. The model explaining the nature of that Stokes shift has been suggested. The inhomogeneity of energy of the electron-hole pair in the volume of the nanoparticles has been taken into consideration.

The PL spectra for the types of samples under studies demonstrate two essentially different behaviours. The changes in the PL spectra observed during the process of photoetching could be caused by the influence of different initial defect structures of the samples, namely the presence of bulk or surface defects.

\section{References}

1. Murray C B, Norris D J and Bawendi M G, 1993. Synthesis and characterization of nearly monodisperse $\mathrm{CdE}(\mathrm{E}=\mathrm{S}, \mathrm{Se}, \mathrm{Te})$ semiconductor nanocrystals. J. Amer. Chem. Soc. 115: 8706-8715.

2. Ptatschek V, Schmidt T, Lerch M, Muller G, Spanhel L, Emmerling A, Fricke J, Foitzik A H and Langer E, 1998. Quantized aggregation phenomena in II-VI semiconductor colloids. Ber. Bunsenges. Phys. Chem. 102: 85-95.

3. Talapin D V, Rogach A L, Mekis I, Haubold S, Kornowski A, Haase M and Weller $\mathrm{H}, 2002$. Synthesis and surface modification of amino-stabilized CdSe, CdTe and InP nanocrystals. Colloids and Surfaces A. 202: 145-154.

4. Yan Y, Li Y, Qian X, Yin J and Zhu Z, 2003. Preparation and characterization of CdSe nanocrystals via $\mathrm{Na}_{2} \mathrm{SO}_{3}$-assisted photochemical route. Mater. Sci. Eng. B. 103: 202-206.

5. Henglein A, 1982. Photo-degradation and fluorescence of colloidal-cadmium sulfide in aqueos solution. Ber. Bunsenges. Phys. Chem. 86: 301-305.

6. Fojtik A, Weller H, Koch U and Henglein A, 1984. Photo-chemistry of colloidal metal sulfides. 8. Photo-physics of extremely small CdS particles: Q-state CdS and magic agglomeration numbers. Ber. Bunsenges. Phys. Chem. 88: 969-977.

7. Dijken A van, Vanmaekelbergh D and Meijerink A, 1997. Size selective photoetching of nanocrystalline CdS particles. Chem. Phys. Lett. 269: 494-499.

8. Dijken A van, Janssen A H, Smitsmans M H P, Vanmaekelbergh D and Meijerink A, 1998. Size-selective photoetching of nanocrystalline semiconductor particles. Chem. Mater. 10: 3513-3522.

9. Uematsu T, Kitajima H, Kohma T, Torimoto T, Tachibana Y and Kuwabata S, 2009. Tuning of the fluorescence wavelength of CdTe quantum dots with $2 \mathrm{~nm}$ resolution by size-selective photoetching. Nanotechnology. 20: 215302 (9 p).

10. Dmitruk I., Barnakov Yu. and Kasuya A. Laser photoetching in nanoparticles preparation and study of their physical properties. In: Low-Dimensional Systems: Theory, Preparation, and Some Applications. Kluwer Academic Publishers (2003): $121-131$.

11. Efros Al L, Rosen M, Kuno M, Nirmal M, Norris D J and Bawendi M, 1996. Bandedge exciton in quantum dots of semiconductors with a degenerate valence band: Dark and bright exciton states. Phys. Rev. B. 54: 4843-4856. 
12. Kasuya A, Sivamohan R, Barnakov Yu, Dmitruk I, Nirasawa T, Milczarek G, Mamykin S, Romanyuk V, Tohji K, Jeyadevan V, Shinoda K, Kudo T, Terasaki O, Liu Zh, Ohsuna T, Belosludov R, Kumar V, Sundararajan V and Kawazoe Y, 2004. Ultra-stable nanoparticles of CdSe revealed from mass spectrometry. Nature Materials. 3: 99-102.

13. Bacherikov Yu Yu, Davydenko M O, Dmytruk A M, Dmitruk I M, Lytvyn P M, Prokopenko I V and Romanyuk V R, 2006. CdSe nanoparticles grown with different chelates. Semiconductor Physics, Quantum Electronics \& Optoelectronics. 9: 75-79.

14. Gaponenko S V, Woggon U, Uhrig A, Langbein W and Klingshirn C, 1994. Narrowband spectral hole burning in quantum dots. J. Lumin. 60\&61: 302-307.

15. Pundyk I P, Dmitruk I M, Kasuya A, Davydenko M O and Romanyuk V R (to be published).

Davydenko M.O., Dmitruk I.M., Pundyk I.P., Berezovska N.I. and Romanyuk V.R., 2010. Effect of size-selective photoetching on the absorption and photoluminescence spectra of CdSe nanoparticles. Ukr.J.Phys.Opt. 11: 147-155.

Анотація. В роботі вивчались спектри поглинання і фотолюмінесценції колоїдного розчину наночастинок CdSe y процесі розмірно селективного фототравлення. Процес фототравлення використовувався для вивчення фізичних властивостей частинок. Оиінене значення однорідного розширення $і$ часу життя резонансно збуджених екситонних станів наночастинок певного розміру. Запропонована модель, яка пояснюе природу стоксівського зсуву і яка приймає до уваги неоднорідність енергетичного розподілу електронно-діркових пар в об'ємі наночастинки. Величина стоксівського зсуву визначена для різних зразків. Різна зміна в спектрах фотолюмінесиениії, яка спостерігалась під час процесу фототравлення може бути спричиненою впливом різних початкових дефектних структур зразків. 